\title{
Ecological and technological criteria for comparing the natural intensity of industrial and municipal waste sites with the technological intensity of the environment
}

\author{
I.A. Shishkin ${ }^{1, *}$, N.A. Zhilnikova ${ }^{1}$, and A.A. Baranova ${ }^{1}$ \\ ${ }^{1}$ Saint Petersburg State University of Aerospace Instrumentation Saint Petersburg, Russia
}

\begin{abstract}
A systematic approach based on environmental and technological criteria has been proposed to ensure the achievement of environmental quality standards of the environment at the regional intersectoral level for the management of industrial and municipal waste. A list of indicators and criteria has been formed for comparing the accumulating capacity of a given natural system without serious violations of its structural and functional characteristics on the one hand. On the other hand, there is production potential and production capacity for natural resources for individual enterprises and a diversified industrial complex. An algorithm for comparing production and natural potentials on the basis of a geographic information basis on the scale of a territorial natural production complex has been developed and the structure of a GIS project has been determined. The latter made it possible to interconnect the natural intensity of production (NP), the level of environmental friendliness of production (EFP), the ecological technological capacity of the territory (ETT) using the criteria of commensuration (NDV, VAT, PDRO and NDT).
\end{abstract}

\section{Introduction}

One of the defining stages in the management structure of the industrial and municipal waste management system is the construction of a general flow diagram for the sectors of the economy involved, with a given geographical coverage, type and hierarchy of waste, and types of environmental impact from landfills. The latter occupy the lowest place in the waste hierarchy due to the minimal and often complete lack of use of waste resources.

However, in accordance with the current environmental legislation, requirements are predetermined for the regulation of all types of technogenic impacts in the form of "Norms of permissible impacts" (NPI) on the environment within the territorial natural production complexes at the regional and inter-sectoral levels. The solution to this problem is associated with the need to compare the natural and production potential of natural production complexes using environmental and technological criteria, create initially ecologically balanced complexes and place industrial and municipal waste sites, subject to the self-preservation of natural ecosystems. One of the main criteria for standardizing the technogenic load for the production share is the level of environmental friendliness, both of individual stages of production of natural production complexes, and natural production complexes in general, as well as the criterion of commensuration and balance of natural and production potentials based on a single information database. The provision of these criteria can be achieved with the help of specialized structures of control subsystems, each of which is determined by the form of spatio-temporal interactions between the elements of a dynamic system. In accordance with the configuration of natural production complexes, the structure of the organization of arrays of diverse information of natural and technical complexes is determined on an intersectoral basis to achieve a balance of natural and production potentials in the form of norms of permissible impacts for each of the impact types within the ecological technological capacity of the territory, integrity, productivity, sustainability of the ecosystem, conservation of species composition, biodiversity and structure of internal relationships. All these criteria are closely interrelated and interdependent and are schematically represented as:

\footnotetext{
* Corresponding author: ilya@mail.ru
} 


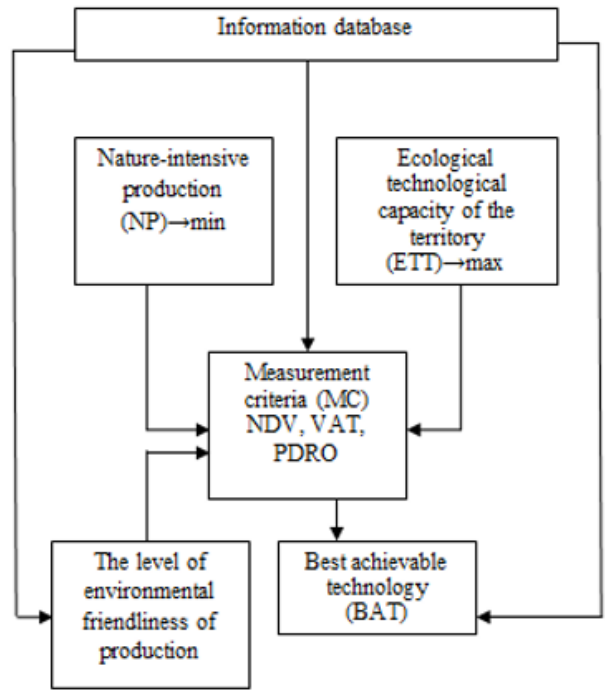

Fig. 1. Relationship diagram NP, The level of environmental friendliness of production, ETT, MC and BAT.

In accordance with the scheme in fig. 1, within the framework of natural production complexes, stable productivity is ensured with maximum ecosystem resistance to technogenic impacts. For the production complex, the nature intensity of production is minimized and the normative relationships between the natural and production potential of natural production complexes are achieved.

In accordance with the Order of the Government of the Russian Federation of December 24, 2014 No. 2674, waste disposal activities are related to the application of the best available technologies. The overall goal is to ensure the environmentally safe management of hazard class IV - V waste generated as a result of production activities and to maintain an acceptable level of environmental impact.

\section{Method and materials}

The basis for the validity of making managerial decisions for natural production complexes of complex configuration are typical submodels and methods of a territorial geoinformation model with an appropriate industrial and technical database about all subjects of natural production complexes.

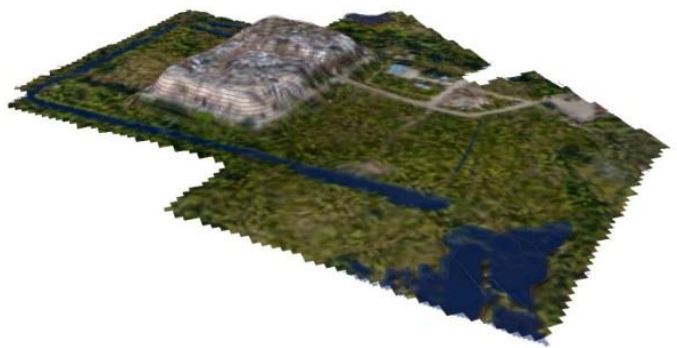

Fig. 2. Volumetric image of the site.

The model of the site of industrial and municipal waste on a geoinformation basis in accordance with the volumetric image in fig. 2 , is structured in fig. 3 to ensure the environmentally safe handling of waste classes IV-V and the formation of a geoinformation database.

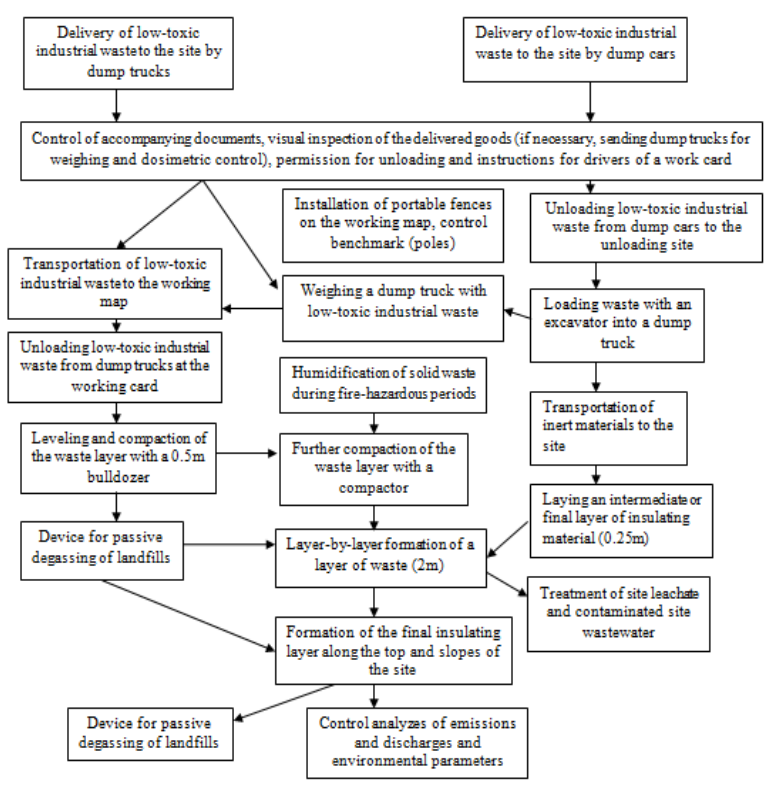

Fig. 3. Structure of functioning of the municipal waste site.

\section{Modeling of processes}

The basis of the geoinformation database includes data on the places and volumes of formation, conditions of processing and disposal of various types of waste. Data on promising best permissible technologies and equipment are summarized. GIS technologies allow at the local (production and technical) and regional (intersectoral) levels to monitor and form a systematized data bank and knowledge base on waste and technologies for the use and disposal of waste. Predictive simulation models allow assessing the negative impact of waste on the environment and human health within the framework of an inter-sectoral regional monitoring system and norms of permissible impacts with an emphasis on recycling rather than disposal of waste. The backbone of the waste processing industry with one control center is a plant on an inter-industry basis for waste processing. The reference information base, on a geoinformation cartographic basis, allows you to enter the places of generation and placement of solid household and low-toxic waste in the region. In addition, information on the amount of waste, its composition, the danger to humans of individual fractions and the entire mass as a whole is entered into the database on an intersectoral basis. 


\section{Semulation of dilution. Formation of a GIS project and obtaining an assessment of the state of the territory for processing and disposal of waste}

GIS technology makes it possible to automate the processes of collecting, processing and presenting data. At the same time, it becomes possible to create systems for monitoring the state of an object, on-line analysis of the course of processes, predicting the development of situations and supporting management decisions.

Let us consider the main stages of the formation of the GIS project "Industrial and municipal waste management", which ensures the automatic implementation of the necessary transformations and algorithms to solve the task - assessing the state of the territory with ensuring environmental performance for a given production solution and regional norms of permissible impacts.

1. Creation of a basic GIS information structure for obtaining estimates.

2. Creation of a geoinformation model of the object allocation of the territorial system of the vehicle and the definition of its target functions, the definition of the structure.

3. Determination of the list of controlled parameters, algorithms for obtaining complex and complex estimates.

4. Formation of a base of algorithms for obtaining simple and complex normalized estimates.

5. Ranking of the analysis results, in order to conduct further surveys and support management decisions.

6. Formation of algorithmic support for calculating assessments of the state of territories - formation of the structure of the GIS project.

7. Presentation of analysis results (GIS layer, tables, diagrams, reporting forms).

8. Solving the problem of the most effective investment in the repair and reconstruction of engineering structures.

The logic of the formation of the GIS project RIS $\mathrm{CO}$, including the relationship between the main stages and the content of the GIS project "Industrial and municipal waste management" is shown in figure 4 .

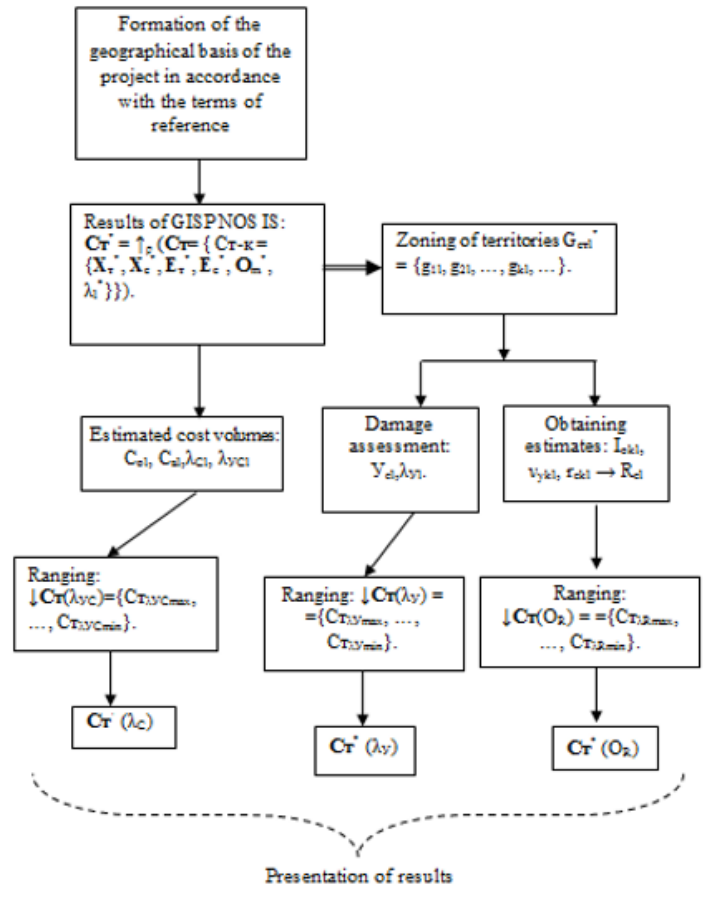

Fig. 4. Block diagram of the logic of the formation of a GIS project.

\section{Conclusion}

Within the framework of the GIS of the Waste Management project, a reference and information system with a developed interface was proposed, which serves as the basis for expert assessments of the sanitary and environmental situation in the region, as well as for making management decisions, taking into account the entire set of determining factors and the possibility of their dynamic change based on modeling and cartographic representation of spatial objects. The use of spatial analysis methods based on GIS technologies allows solving the problems of accumulating, storing, analyzing any spatio-temporal information, building predictive models, creating scenarios of possible situations, etc.

In the GIS project for ranking the information system according to the degree of efficiency, the following are analyzed: the region, its affiliation, the structure of the information system "Waste Management", the design characteristics of the targeted use of the territory and the calculated characteristics of all information systems for waste management. The geodatabase describes waste management information systems in accordance with the developed model.

Thus, the paper proposes an information management system for waste management using geoinformation technology at the local and regional levels with appropriate databases.

The structure of the geoinformation database has been formed by defining indicators and indices. A waste processing plant was identified as the center of interindustry management.

Eight main stages of the formation of the GIS project "Management of industrial and municipal waste" with 
the possibility of automated implementation of the necessary transformations and algorithms for the optimal comparison of the integral criteria of the natural intensity of the industrial complex and the ecological technological capacity of the considered territorial ecosystem in the zone of a certain territory of industrial and municipal waste sites have been identified.

In accordance with the logic of the formation of GIS projects, the simulation model makes it possible to assess the rate of development of production and the adaptive capacity of the natural environment. It is obvious that the economic damage is determined not only by the withdrawal of natural resources, but also by their pollution, which, accordingly, is associated with the value of the particular indicators of the natural resource intensity and is illustrated by the diagram in fig. 1,3,4 in the framework of real GIS projects and are expressed by the mass of the substance by the effect of toxicity.

\section{References}

[1] A. Chusov, V. Maslikov, D. Molodtsov, O. Manukhina, Determination of Environmental Impact Factors of Flood Control Hydrosystems with Temporarily Filled Self-regulating Reservoirs, Advances in Intelligent Systems and Computing 692, 1046-1054 (2018)

[2] A. Shishkin, A. Chusov, M. Epifanova, D. Silka, Functional Model That Evaluates the Impact of Hydrotechnical Works and Facilities on a Water Object, Advances in Intelligent Systems and Computing 692, 921-935 (2018)

[3] A. Chusov, I. Shishkin, A. Epifanov, I. Kochetkov, Development of the open drainage network of St. Petersburg suburbs on the basis of GIS technologies, IOP Conference Series: Earth and Environmental Science 90, 1, 012232 (2017)

[4] Kh.V. Il'ina, N.M. Gavrilova, E.A. Bondarenko, M.Ju. Andrianova, A.N. Chusov, Expresstechniques in study of polluted suburban streams, Magazine of Civil Engineering 76, 8, 241-254 (2017)

[5] E.A. Bondarenko, Kh.V. Ilìna, M.Ju. Andrianova, A.N. Chusov, Main inorganic ions and electric conductivity of polluted urban streams, Magazine of Civil Engineering 68, 8, 37-44 (2016)

[6] M.J. Andrianova, K.V. Vorobjev, J.A. Lednova, A.N. Chusov, A short-term model experiment of organic pollutants treatment with aquatic macrophytes in industrial and municipal waste waters, Applied Mechanics and Materials, 587-589, 653-656 (2015)

[7] M.J. Andrianova, E.A. Bondarenko, E.O. Krotova, A.N. Chusov, Comparison of chemical and optical parameters in monitoring of urban river Okhta, EESMS 2015 - 2015 IEEE Workshop on Environmental, Energy and Structural Monitoring Systems, Proceedings 13 October 2015, 6923291, 198-202 (2015)
[8] G.A. Kondrashkova, I.A. Shishkin, Method of regulation taking into account environmental risk criteria, Sat. Organization of environmental protection, improving the efficiency of environmental management and environmental safety, Saint Petersburg, 245-250 (2016)

[9] A.V. Epifanov, I.A. Shishkin, E.V. Vasukova, A.I. Shishkin, Basin standardization of technogenic load by methods of imitative modelling, Italian Russian institute of education and ecological researches, 3 rd. Simposium «Quality and Management of Water Resources, Saint Petersburg, 99-107 (2015)

[10] N.V. Arefiev, V.P. Breusov, G.K. Osipov, Fundamentals of the formation of natural-ecological systems, Theory and practice (Saint Petersburg, Polytechnic Publishing House University, 2016) 432

[11] N.V. Arefiev, V.L. Badenko, N.K. Latyshev, Geoecological approaches to the development of information and analytical systems for irrigation and drainage construction and environmental engineering, Scientific and technical statements of SPbSPU 4, 205-211 (2016)

[12] V.V. Dmitriev, G.T. Frumin, Environmental regulation and sustainability of natural systems (Saint Petersburg, Nauka, 2017) 294

[13]I.A. Shishkin, Presentation of the system of engineering protection of the territory from flooding in GIS for the purpose of automating the assessment of their condition, ISTC Science-intensive and innovative technologies in solving the problems of forecasting and preventing emergencies and their consequences, Saint Petersburg, 47-52 (2018)

[14] M.P. Fedorov, Ecological foundations of management of natural and technical systems (Saint Petersburg, Publishing House of the Polytechnic University, 2017)

[15] V.V. Alekseev, Information measuring systems. Comprehensive assessment of the state of objects in the natural environment on the basis of GIS technologies, Bulletin of Education and Science Development of the Russian Academy of Natural Sciences 5, 3, 230-240 (2018)

[16] V.V. Alekseev, N.V. Orlova, IIS for monitoring the state of natural objects, Ensuring the uniformity of measurements in obtaining estimates based on control measurements: Devices 2, 19-28 (2016)

[17] A.I. Shishkin, Environmental quality management using geographic information systems (Saint Petersburg, Publishing House of the Polytechnic University, 2017) 